\title{
The Travali of Criminal Thinking, a Psychoanalytic Interpretation of the Absence of the Superego
}

\author{
Gabriel Tanasescu \\ University of Craiova, Craiova, Romania, gabrieltanasescu@gmail.com
}

\begin{abstract}
The human being (the active subject of the crime of murder) cannot commit the crime unless it has first killed the suzerain. As long as the suicide still exists and is present in the being, crime cannot be achieved, it cannot become reality, as individual is not prepared to act to commit the criminal act. Hate, evil, aggression build up in consciousness when the suzerain begins to die gradually. Deicide is not only the killing of God by its own being, but also the death of superstition, the killing of the images of ideal parents, the death of any symbol representing ethics, the assassination of the moral court, and all the positive feelings of the individual engaged in society, the realization of existential projects. The construction of the criminal personality is born only after the neurotic ego has killed its own moral court. This is easy when the overhead is not strong, that is, it does not manifest itself as a true barrier, supreme inhibition, in the face of existential pulses.
\end{abstract}

KEYWORDS: aggressiveness, criminal, criminal personality, neurotic self, superego

\section{Introduction}

The human being (the active subject of the crime of murder) cannot commit murder unless he first killed the Superego. As long as the Superego (Superego) still exists and is present in the being, crime cannot be achieved, it cannot become reality, the individual is not prepared to act to commit the criminal act. Hate, evil, aggression builds up in consciousness when the Superego begins to die gradually. Deicide is not only the killing of God from its own being, but also the death of the Superego, that is, the killing of the images of the ideal fathers, the death of any symbol representing ethics, the assassination of the moral court and all the positive feelings of the individual engaged in society, the realization of existential projects.

\section{Considerations of delinquent behavior}

The construction of the criminal personality is born only after the Neurotic Ego has killed its own moral court. This is only possible when Superego is not strong, that is, it does not manifest itself as a true barrier, supreme inhibition, in the face of existential pulses.

There are real situations when the Superego has not formed in the individual, when it is very absent and in a permanent state of concealment. The lack of education and family affection leads to the absence of the idealizing image of parents and teachers and can pave the way for inferiority, school abandonment, the suppression of positive projects on social integration, the emergence of sexual deviance and the formation of aggressive personality. These negative germs are revealed in the immature being insufficiently prepared to discover their present value. If the Superego has formed as a moral instance in being, it is very difficult for the individual to become a delinquent or aggressor. The loss of social position, economic, legal and emotional advantages, the success achieved through the individual's commitment to the community where he expresses and manifests reality and gains positive experience, happens only incidentally, exceptionally; there are statistically much fewer offenders coming from this category of society.

The gradual construction of a positive destiny, happy childhood, complete school and civic education, family life based on love and respect, professional careers, and good financial results prevent the individual who enjoys these achievements from becoming a criminal. To maintain and give value to professional and family careers, the individual does not normally have the preoccupations and time needed to carry out the criminal career. The delinquent self coming from this category was accidentally corrupted, being just an exception. Corruption in this case is an accident and not an imitation of negative behavior within society. The risk of a person who has never committed crimes of losing everything he or she has created at the professional, financial and family level, to compromise 
him- or herself in the middle of the community is weighed very well by the moral and social function of the personality, making it usually impossible for behavior aggressed-offenders.

It is impossible to kill if you did not kill your Superego. Intra-family violence (marital) occurs in critical divorce situations, lack of financial means that can lead to family breakdown, alcohol or drug poisoning, adultery and sexual deviance. The psychoanalytic explanation shows us that the criminal ego is enslaved by the existential pulses of the Se (Id) becomes the victim of Morality Absence, is the slave of inner disorder, aggressive motivation does not represent an indispensable physiological need, but rather a satisfaction of the mental discharge of pulsational tensions of death. "People who are gentle, care about other people, wish them good have a happier and more solid marriage. Stability is a marriage predictor due to the fact that a stable emotional person has a lower predisposition to conflict than an unstable person, which makes marriage problems solved by peaceful methods rather than verbal / physical conflicts or aggressions" (Anitei, Chraif, Burtaverde and Mihaila 2016, 282). In the case of the triple murder in Brasov (March 2018, a father kills with discernment, with several knife blows at different time intervals, the wife and the two teenage children, the girl and the boy, without explanation) the emotional instability of the killer and the consumption of the drugs have made it possible to completely inhibit the moral function, the Criminal Ego chooses the realization of the act being unable to control the trigger event of the crime.

The antisocial personality disorder "is strongly correlated with criminality, and this behavior has led clinicians to characterize individuals with this type of disorder as insensible, incapable of love, learning from their own experiences, and without shame and remorse" (Anitei, Chraif, Burtaverde and Mihaila 2016, 305).

\section{The influence of Superego activity on the killer's personality}

Freud's psychoanalysis tells us that regardless of the genetic heritage of Se, the personality of the killer is measured only by the Superego's performance. Whether something is forbidden, Se (Id) needs pleasure and requires the Ego to obtain it without taking into account the consequences. In this situation Superego censorship must intervene; but if the needs of the Se are stronger, the Ego, dominated by the pulsations of the primitive beings, will only act to satisfy the imperative desires of the Se. The idealistic image of parents, the remorse of never disappointing them, moral norms and principles, existential values, school and civic education, the desire not to disappoint teachers and friends, these things build the power of Superego to get out of hiding and darkness the presence of the Ego. Without the power of the Supreme, the Ego will never be strong and will always be dominated by destructive pulses. The superstition of his moral laws and principles can sometimes put too much pressure on the Ego, it can exhaust and unbalance, the Superego's requirements becoming as damaging as the Se's pretensions.

In the Psychoanalysis Compendium, Sigmund Freud describes the nature of the psychic factor, considering that the Ego is a special development of the Se, the latter the Se (Id) being the oldest psychic instance; its content is all inherited, born, constitutionally established. The self becomes an extension of the Se, a special organization that mediates between him- or herself and the outside world (Freud 2016, 87).

The imminent criminal act, the crime obsession, the aggressive act of aggression is so intense that it chokes the Ego and forces it to go through the act to get rid of the force of the pulse of death (destructiveness) that breaks its being. No release of the act leads to suicide or insanity (Freud 2014, 66). The role of transferring aggressive personality to educator, therapist, or probation officer is very important. Discharging crime means getting rid of aggression.

The evil is only a private deprivation (privatio boni) - St. Augustine. The social existence of human shows us that human in his primacy is a being of good.

The primordial human being is the being of good, and (antithesis) is emphasized by Erich Fromm in the Anatomy of Human Destruction (Fromm 2015, 24), "man is the only primate who kills and tortures members of his own species without any biological or economic reason, and who feels pleasure doing that."

Freud believes sometimes that crime is an eternal return to the release of evil (Freud 2016, 53). The evil as a death pulse subjugates the being of the killer. The killer does not regard the victim as a 
being, depersonalizes it, takes it out of the world. The victim does not have personality, is without will, and the existence belongs to the aggressor. The assailant is mastering and giving it only when the criminal act is committed. The victim has no soul, spirit, because the killer in his egocentrism believes he is the prolongation of the victim's ego.

Criminal is defined by its absolute reality that contains both the victim's presence and the social reaction (Tănăsescu 2012a, 111). Crime is happening in the world, the social reaction being the expression of the world's manifestation. Only a false, dead world does not react to the crime. By the way of thinking, the criminal is the one who creates and develops the criminal phenomenon, the victim and the social reaction, the world in which the crime occurs and how to achieve the act. Crime can only be brought in by criminal thinking (one of the purposes of ego criminology is the uninterrupted study of criminal thinking). The content of criminal consciousness is even the manifestation of his thought in society, the criminal act being described even the criminal reality. Thinking in the absence does not analyze itself, aggression is a fall of the being in the darkness of its absence.

The healthy and sexually satisfied individual will not commit crimes in order not to lose the privilege of pleasure (libido). Sexual pleasure is thus transformed into social pleasure to be positive in the community. Social engagement becomes important and motivational because it preserves the useful, pragmatic position of the individual in society with a partner. This pulse of life can be manipulating, the one dependent on her sexual life (love for her partner) will try to do anything to keep this advantage. Sometimes the stronger partner can control the behavior of the other. "Aggression was considered secondary to sexuality. It was subordinate to sexuality" (Lagache 2003, 16).

The sexually unlucky person with an antisocial personality has nothing to lose, has no privilege of fulfilling intimate life, has no respect for himself or his community, has no organized family, or has a stable relationship with a partner, thus making the offense much easier - Anti-seizure. "People get sick if they are actually refused to meet their erotic needs because of external impediments or lack of internal adaptation" (Freud 2016, 63).

The perpetrator is not concerned about the future, his or her historical-existential destiny, the realization of projects involving long-term commitments; he or she is not obsessed with his health, nor is he or she concerned about the consequences of a negative life; he or she is not interested in the philosophy of death and eternal life; lives today but without presentence (the essential presence of being conscious of his role in the world); is under the control of his immediate pulses and wishes to do it impatiently; the fear of being caught, the anguish of criminal conscience must be interpreted as a delay in the awareness of the criminal sanction, as a avoidance of the state of detention; the satisfaction of preventing criminal law from producing its effects through judgment and execution of punishment (play with criminal investigation organs explains the addiction of the Ego to the inner pulse of the Se and the deregulation of moral function).

The delinquent is not afraid of the punishment of society because he or she feels thrown into society without justification, existential failure in the middle of his community gives him or her the opportunity to commit crimes easier, the decision is taken without any constraint of inhibition, because he or she does not he also has inside or barrier the values that would stop him or her at the moment of passing the act. Having no social value, without appreciating him- or herself and without respecting the others, the offender commits without fear the crime because he or she does not have a position in the society that he or she could lose, he or she does not have apparatus privileges, is a pariah tries to do it without being able to build an existential project that would engage him or her in a positive social relationships that would oblige him or her to respect general conduct (Tănăsescu 2012b, 125).

This antisocial behavior is possible because the psychoanalytic interpretation shows us that the individual's supergod has begun to die, or when the inhibition no longer exists, we can say that the Superego has been definitively killed. Divine punishment cannot affect the delinquent, because God has disappeared from his or her life, the deicide occurs at the egocentric awareness of the aggressor's power in front of the victim. The victim has the significance of the sacrifice to the ego-centric will of the murderer to satisfy the death-pulses of the Sega, acting as the Supergod. The victim defines the passage to the criminal act. The reproach of ideal parents, their coercive behavior, the attitude of the family that is correct and appropriate to social norms can no longer influence the delinquent because by 
the death of the Superego the individual gives up the positive family climate, rejecting this past inhibitor that could create problems in the moment the aggressive trigger event occurs, the ethic is hidden and looked unconscious.

If the family experience during childhood was negative, aggressive, with the consequences of juvenile violence, then Superego was incapable of developing, psychological trauma essentially marking the delinquent behavior of the future adolescent-adult. "The energetic, successful and accomplished man is the one who succeeds in translating the work of fantasy-desire into reality. Where this does not succeed because of the resistance of the outside world and the weakness of the individual, it moves away from reality and withdraws into the more satisfying fantasy world whose content transposes it in the event of illness in symptoms" (Freud 2016, 64).

The sanction of the law does not frighten the delinquent, because it accepts the probability of the detention, but does everything possible to postpone this moment. Reaching offenses are natural concerns of the offender's existence. Because he did not find the usual joy of being useful to society and to feel the satisfaction of carrying out a project or concluding a social commitment, the offender abandons licit labor and lives the mediocre happiness in carrying out various criminal operations.

"In general, the more intense the emotions are, the more likely they are to dictate their actions" (Bradberry 2016, 24).

Freud through "Neuroscience of Destiny" describes quasi-identical events when they are unfavorable (men mistreated by their mistress).

The detention facility is unnecessary and costly if the damage in all its forms to the victim and the community is not fully recovered and the offender is not fully rehabilitated and reintegrated to normal, positive society, ready to respect the rules and creates opportunities for his or her valuable role in family and community. Detention specialists believe that the penitentiary must exist only for recidivists, very aggressive people who do not want cooperation with educators and psychotherapists who refuse treatment and social integration and choose as a way of life criminal life (statistically they represent the lowest percentage of offenders). Young people and those who have committed less serious offenses can execute punishments in special, private or non-custodial institutions.

Aggressiveness means lack of word, language. The aggressor is an individual whose words are dead or die. Communication with the aggressor is not done through weapons, so we have relapses and failure of social reintegration in prisons. In detention the killer must learn to speak a social language again. The social language absent in the offender's being is born with the hideout of the positive personality. The personality of the criminal ego must be replaced by the personality of the social ego. This metamorphosis occurs only in an area dedicated to education, where the offender's positive destiny is projected.

Without a social history, the offender acquires in this space a historical being (unloved, unwanted, unloved children, absent, aggressive parents, rediscovering their personality in this space). Delinquents have to learn, with the help of educators and therapists, to discover their own emotional intellect, "being able to recognize and understand their own and others' emotions and the ability to use this consciousness to manage behavior and relationships" (Bradberry 2016, 24).

\section{Conclusions}

Reforming the Supra depends on the destiny's destiny. Sometimes in the detention area, the convicted can deepen his or her inability to adapt, refusing treatment and methods of learning social reintegration, or sequentially discover the opening of those concerned about the fundamental change of the incarcerated persons.

A religious person, a trustworthy partner, an educator, or an instructor instructed to teach the detainees a job and prepare them for their own use and for society, may change the historical trajectory of the existence of individuals who are convinced that they are can turn positive. "The ego tends to pleasure, wants to avoid unpleasantness" (Freud 2016, 75). To enjoy a free presence in the middle of society is the first step to healing the one condemned for the wrong decisions of the delinquent ego, so that the delinquent recovered and rehabilitated makes it possible for "everyone's freedom to coexist with that of others" (Kant 1994, 285). 


\section{References}

Aniței, Mihai, Mihaela Chraif, Vlad Burtaverde, and Teodor Mihăilă. 2016. Personality Psychology Treaty. Bucharest: Three Publishing House.

Freud, Sigmund. 2014. About Psychoanalysis. Bucharest: Three Publishing House. German translation Daniela Stefanescu. Freud, Sigmund. 2016. Collective Psychology and Self-Analysis. Bucharest: Cartex Publishing House, English translation Lucian Pricop.

Fromm, Erich. 2015. Anatomy of Human Destruction. Bucharest: Three Publishing House.

Kant, Immanuel. 1994. Critique of Pure Reason. Bucharest: IRI Publishing House.

Lagache, Daniel. 2003. Psychoanalysis. Bucharest: Corinth Publishing House.

Tănăsescu, Camil. 2012a. Criminology. Bucharest: Universul Juridic Publishing House.

Tănasescu, Camil. 2012b. Judicial Psychology. Bucharest: Universul Juridic Publishing House.

Bradberry, Travis and Jean Greaves. 2016. Emotional Intelligence 2.0. LITERA Publishing House. English translation by Irina Brates, digital version. 